\title{
APROXIMACIÓN A LAS FORMAS DE TRATAMIENTO DEL SIGLO XVI EN LA PENÍNSULA IBÉRICA (METRÓPOLI) Y EN LA NUEVA ESPAÑA
}


El propósito de este artículo es identificar las formas de tratamiento empleadas en la península ibérica (Metrópoli) y en la Nueva España (siglo XVI), a través de la descripción de su interacción sintáctico-gramatical. Se presenta un modelo conformado por ocurrencias de relaciones sintagmáticas en el plano del enunciado, tomadas de un corpus de 50 mil ítems, extraídos de obras literarias, epistolarios, corpora electrónicos y documentos pertenecientes al coreecom (Corpus Electrónico del Español Colonial Mexicano). Se han agrupado por país y clasificado en función de su uso. La existencia de diversos estamentos marca una distinción en el uso de los tratamientos. Aunado a esto, las disposiciones monárquicas relacionadas con la manera en que debía tratarse a los interlocutores de mayor jerarquía, permite confirmar la existencia de por lo menos dos ámbitos de uso, así como demostrar que cuando el hablante establece un discurso asimétrico emplea diversas gramaticalizaciones, tantas como necesite, para emitir una forma o fórmula de tratamiento, que puede involucrar hasta cuatro o cinco categorías gramaticales distintas.

Palabras ClaVe: formas de tratamiento, fórmulas de tratamiento, español colonial, siglo XVI, interacción diádica, deferencia

The aim of this paper is to identify the addressing forms used in the Iberian Peninsula (Metropolis) and New Spain (xvi Century), by quoting passages and describing their syntactic and grammatical interaction. Hereby, we have a compilation of syntagmatic relationships between sentences in text. They come from literature, epistolary genre, and electronic corpora like COREECOM (for their initials in Spanish for Mexican Colonial Spanish Electronic Corpus). The examples had been classified by geographic area and pragmatic use. The social stratification proposes a distinction in the use of addressing forms. Besides, the Pragmatic Sanction of 1568 by Philip II, related with the way someone was required to speak and write to a person in a higher position, demonstrates that the speaker sets an asymmetric discourse, using different grammaticalizations, as many as they need, in order to use an addressing form that might include even four or five different grammatical categories.

KEY WORDS: addressing forms, forms of address, colonial Spanish, XVI Century, deference, dyadic interaction 


\title{
APROXIMACIÓN A LAS FORMAS DE TRATAMIENTO DEL SIGLO XVI EN LA PENÍNSULA IBÉRICA (METRÓPOLI) Y EN LA NUEVA ESPAÑA ${ }^{1}$
}

\author{
María Guadalupe Juárez Cabañas \\ Universidad Nacional Autónoma de México
}

\section{Preliminar}

Las formas y fórmulas de tratamiento son un conjunto de ítem léxicos y gramaticalizaciones que el hablante emplea para dirigirse a un interlocutor; están estrecha y directamente vinculadas con las normas sociales y culturales.

Su uso nos permite establecer tratamientos simétricos/asimétricos a través de diversos factores, uno es por la posición de un nombre frente a un título, inclusive, en la familia. Por ejemplo, los padres, los abuelos, los tíos, son nombrados por el título familiar, mientras que ellos responden por el nombre al miembro más joven de la familia. Del mismo modo, el médico llama por el nombre de pila a la enfermera, mientras

\footnotetext{
${ }^{1}$ La realización de este trabajo ha sido posible gracias a la beca concedida por el Conacyt, para el programa de Doctorado en Lingüística de la Universidad Nacional Autónoma de México, del cual formo parte.
} 
que ésta le responde con doctor. El sacerdote es padre para los fieles pero responde con el nombre de pila o el patronímico del feligrés. El patrón llamará por el apellido o el nombre a su empleado, en tanto que éste le dirá señor.

Cada individuo está en medio de una red social en la que recibe distintos tratamientos, desde el más distante de señor con que nombramos a un desconocido, a la vocación múltiple (variedad de nombres) que prodigan el afecto y la confianza: apócopes, aféresis, hipocorísticos, etc. Entre un extremo y otro quedan los roles sociales y familiares: Pedro es Pedro o mi amor para su mujer, pero es papá para su hijo, tío para el sobrino, profesor para los alumnos, doctor en su consultorio, señor García en el banco, etc. (Castro, 2001).

En este artículo la nomenclatura es como sigue: "fórmula de tratamiento" será aquella que es abierta, no consolidada, y se emplea para dirigirse a un interlocutor; las emplean los hablantes para sustituir a las interpretaciones convencionales (que serían las "formas de tratamiento") y se "moldean" de acuerdo con la necesidad de alejar o acercar al interlocutor, llevando a cabo así la conformación de un tratamiento "no convencional", acorde con las normas sociales del momento.

Las formas de tratamiento, serían las expresiones "consolidadas" para dirigirse a un interlocutor. Esta fórmula puede ser fija, como los títulos de profesiones, títulos de parentesco (padre, madre, hijo, hija, sobrino, etc.); establecida, como [POSESIVO + NOMINAL], en la que los posesivos de segunda de singular y plural son aceptados, y no siempre los de primera, por ejemplo vuestra majestad, su majestad, * mi majestad, mi señor, mi rey; básicas, como las elementales para dirigirse a un desconocido joven o mayor (joven, ca- 
ballero, señor); heredadas, como las que se transmiten, por tradición oral de familia en familia, por ejemplo, cuando a las abuelas se les da un [TÍtUlO DE PARENTESCO + HIPOCORÍstico]: mamá Chole, mamá Lupe.

...las formas de tratamiento son la manifestación de "superficie" (audible en conversación, visible en lectura) de las consideraciones "profundas" - la(s) identidad(es) del hablante, los objetivos conversacionales y los mecanismos para operacionalizar mejor esos objetivos (Oliveira, 2010: 63).

Los tratamientos se pueden estudiar como: nominales y pronominales, connotativos y denotativos, gramaticalizados y verbales, simétricos y asimétricos, por mencionar algunas clasificaciones. Viéndolo de esta manera, hasta cierto punto, pudiera parecer un conjunto cerrado y limitado de opciones, pero no es así: cuando un hablante desea dirigirse a una persona a quien no considera "su igual", puede agregar a los tratamientos tradicionales por excelencia cualquier elemento gramatical que considere conveniente para que le permita "alejar" o "elevar" a su interlocutor.

Es preciso recordar que al llevar a cabo un estudio diacrónico de las formas y fórmulas de tratamiento, una obvia desventaja es que no hay hablantes vivos, contamos solamente con obras literarias, el género epistolar y los textos jurídicos. En el género literario pervive el habla del autor; en los dos siguientes ámbitos, se tiene, por lo regular, la reinterpretación del escribano o del escribiente. Sin embargo, estudiar el pasado de las formas de tratamiento a través de esta variedad de textos tiene sus beneficios: están escritos por 
hablantes contemporáneos de la lengua; en las obras literarias, particularmente, puede entrar todo el espectro social, contexto, elementos prosódicos y kinésicos (véase Moreno, 2010: 84-85). Además, es de vital importancia conocer la historia social de los periodos que se analizan para encuadrar el análisis y las conclusiones.

Los ejemplos de donde parte este estudio fueron tomados del CORDE, ${ }^{2}$ de textos del COREeCOM, ${ }^{3}$ de epistolarios ${ }^{4}$ y textos literarios; en este artículo, la procedencia de cada ejemplo se asienta al final. Con respecto a los corpus electrónicos y de acuerdo con Medina Morales:

...no podemos dejar de mencionar las posibilidades que están aún por descubrir, de los corpus, sean textuales u orales, sean generales o diseñados con fines específicos, como una futura herramienta tanto para los estudios sincrónicos como diacrónicos de las formas de tratamiento. En concreto destacan los corpus electrónicos por su disponibilidad y capacidad de almacenamiento de datos [...] en el caso concreto de los estudios sobre formas de tratamiento, no se han usado estos corpus electrónicos en trabajos con un enfoque sincrónico o actual -ni siquiera se usan, en general los corpus orales, pues, en la recogida de los datos, la mayoría continúa atrincherada en la metodología sociolingüística del cuestionario- y, en el caso de los trabajos diacrónicos, empieza a ser tenido en cuenta el CORDE, aunque aún se cita en muy pocos trabajos (Medina, 2010: 33).

\footnotetext{
${ }^{2}$ Corpus Diacrónico del Español, de la Real Academia Española de la Lengua, disponible en <http://corpus.rae.es/cordenet.html>.

${ }^{3}$ Corpus Diacrónico del Español Colonial Mexicano disponible en <www.iifl. unam. $\mathrm{mx} /$ coreecom/>.

${ }^{4}$ Cartas de Enrique Otte, 1996.
} 
Este artículo se desprende de un proyecto mayor sobre las formas y fórmulas de tratamiento. ${ }^{5} \mathrm{Si}$ en la península ibérica (Metrópoli), en los períodos de estudio, las formas y fórmulas de tratamiento corresponden a determinados estamentos o responden a las necesidades de cierta conformación social, estas formas y fórmulas cambiaron en la Nueva España por la propia estructura social y por el contacto con el nuevo mundo y sus nuevos elementos. En la Nueva España el alejamiento con las dignidades es mayor: a más distanciamiento, se prevé un mayor uso de formas y fórmulas compuestas.

El propósito de este documento es asentar y describir los usos de las siguientes formas de tratamiento que fueron empleadas en discurso simétrico/asimétrico tanto en la península ibérica como en la Nueva España, en el siglo xvi: alteza, señor/a, padre/madre/hijo/hija. A través del registro de éstas, se pretende mostrar la diferencia entre su uso pragmático y referencial. Mencionaré, además, las relaciones sintagmáticas en el plano del enunciado, su uso en contexto conforme lo permita el documento original y referiré algunos de los hallazgos detectados en cada región para el período que nos ocupa en este artículo. ${ }^{6}$

${ }^{5}$ Discurso simétrico vs. discurso asimétrico. Formas y fórmulas de tratamiento
durante los siglos XVI, XVII y XVIII en España y México, Instituto de Investiga-
ciones Filológicas, Universidad Nacional Autónoma de México, Conacyt, CB
2012,180245 .
${ }^{6}$ Aunque el siguiente registro no se asienta en el presente documento, es ne-
cesario destacar que en la investigación de donde parte este artículo, el corpus
se catalogó de la siguiente manera: se agruparon las ocurrencias por siglo (se
analizan los siglos XVI y XVII), y se estableció la siguiente clasificación debido a
los ámbitos de uso de las ocurrencias:
a. Monárquico (M) - en este rubro se agruparon las formas y fórmulas 
En este espacio intento revelar cómo se relacionan, en los diversos estratos, dos variables: el vínculo entre los interlocutores - relaciones simétricas/asimétricas-, y formas y fórmulas de tratamiento.

Metodológicamente, un estudio diacrónico se opondría a uno sincrónico, sin embargo, para revisar con meticulosidad los ejemplos obtenidos y las características de las formas coincidentes en la península ibérica y en la Nueva España tanto en su uso pragmático como en su uso referencial, será necesario hacer una revisión con matiz sincrónico. Cabe aclarar que la investigación de donde parte este artículo no es una agrupación de características sincrónicas por etapa, debido a lo siguiente: las ocurrencias se agruparán por sus ca-

empleadas para dirigirse a la realeza, tanto de forma pragmática como referencial.

b. Jurídico-administrativo (J-A) - las ocurrencias pertenecientes a juicios, demandas, solicitudes gubernamentales, y otros relacionados con el derecho y la administración.

c. Familiar-amistoso (F-A) - en éste se conjuntaron las formas y fórmulas que pudieran ser menos ceremoniosas, propias de una conversación entre pares.

Dentro de los ámbitos anteriores, se detalló por emisor, determinando:

a. Estamento/clase social.

b. Género.

Con la división anterior, se detectó que además de las formas de tratamiento tradicionales, los hablantes empleaban diversas categorías gramaticales que agregaban a la forma de tratamiento "base", logrando con esto diversos sintagmas de estructuras morfosintácticas muy particulares. Se llevó a cabo el registro de estos hallazgos.

Con los resultados anteriores, cada grupo de formas se analizó considerando los factores extralingüísticos de la época, para poder determinar su evolución dentro del marco lingüístico de cada región.

Cada una de las ocurrencias se marcó con las iniciales del ámbito al que corresponden para observar si es posible llevar un conteo de formas únicas por ámbito de uso. 
racterísticas pronominales y nominales y se clasificarán por su uso pragmático y/o referencial. En ella, se hará un análisis de los resultados sincrónicos para ver las diferencias que guardan entre sí y explicar el proceso de cambio que se ha dado; cuando se obtenga este resultado, probablemente será posible establecer convergencias y divergencias entre las formas de tratamiento de la península ibérica y la Nueva España.

Al llevar a cabo una comparación entre las formas de la Nueva España con las de la península ibérica, es posible aproximarse a la evolución de las formas de tratamiento empleadas en Nueva España en el período de estudio.

Para lograr este objetivo fue necesario revisar el panorama histórico de la teoría y metodología de las formas y fórmulas de tratamiento, y las perspectivas más relevantes, proyectadas en varias décadas, entre otros: el poder y la solidaridad de Brown y Gilman (1960); los estudios sociolingüísticos sobre tratamientos de Fontanella de Weinberg (1970 y 1971), Lastra de Suárez (1972), Rigatuso (1987); la sociolingüística histórica Fontanella de Weinberg (1999), García Moutón (1999), Rigatuso (1992 y 1993); los primeros trabajos teóricos sobre tratamientos Medina López (1990); y finalmente los corpus electrónicos como fuente de datos De Jonge (2005); así como las obras literarias Carricarburo (1999), Medina Morales (2002).

Es importante aclarar que, si bien Brown y Gilman, y Brown y Levinson marcaron una época con sus investigaciones y éstas fueron el punto de partida para muchos estudios, en este caso no se han considerado como base metodológica; tampoco hago mención de los ámbitos de poder y solidaridad, debido a que: 
Los factores subsumidos en la dimensión del poder (p. ej., respeto, deferencia, autoridad, posición superior / inferior, etc.), así como los factores subsumidos en la de la solidaridad (p. ej., igualdad de posición, solidaridad, intimidad, confianza, etc.), no son considerados equivalentes por los hablantes; es decir, ejercen fuerzas diferentes en la situación comunicativa y, en algunos casos, son valores muy distintos a otros factores en la "misma" dimensión, resultando una sobrecarga semántica de las categorías de poder y solidaridad (Oliveira, 2010: 65).

Para lograr los propósitos mencionados, este texto se ha dividido en los siguientes apartados: 1) contexto social; 2) formas coincidentes vs. diferencias en la península ibérica y Nueva España; 3) ocurrencias de relaciones sintagmáticas; 4) conclusiones.

Con relación al uso del CORDE, me parece necesario establecer los términos que emplearé para mencionar información en cuanto al número de ocurrencias encontradas: será "búsqueda simple", cuando haya escrito solamente el nominal en la búsqueda, especificando el siglo (1500 a 1599) y el lugar de estudio (península ibérica o Nueva España).

El término "búsqueda avanzada" se referirá a los casos en los que, a través de los operadores lógicos y criterios de distancia indicados por el CORDE, se precisa una búsqueda refinada. Ejemplo: "señor dist/10 te" es la indicación para que el motor de búsqueda sea: encontrar la palabra señor a una distancia de diez palabras del término te; el corpus localizará a partir de 10 y hasta cero palabras de distancia, en orden descendente. 


\section{Contexto social}

El contexto social como elemento condicionante en el uso efectivo del lenguaje es determinante en el momento de distinguir al interlocutor con el que un hablante se relaciona conversacionalmente: tratarlo con familiaridad, distancia o formalidad depende de la mayor o menor confianza que exista, del mutuo conocimiento, del contexto, de la situación, de la interacción comunicativa y de las redes sociales que caracterizan a las diferentes comunidades de hispanohablantes.

El fenómeno de los tratamientos se toma en cuenta, también, desde un punto de vista gramatical, observando los contextos sintácticos que caracterizan la presencia de estas formas y que permiten diferenciarlas del resto del sistema pronominal y nominal.

El sistema de las formas de tratamiento recibe en cada época una organización distinta, dependiente de la estructura social. En él imprimen su huella las transformaciones operadas en el seno de la sociedad. Se podría considerar que es un fenómeno sujeto a cambios, influenciado por factores extralingüísticos. Por lo tanto, las causas de estos cambios debemos buscarlas en la acción de tendencias colectivas de carácter social, que son las que provocan las modificaciones y ajustan el sistema a las necesidades de la sociedad que lo utiliza.

Las relaciones no recíprocas tienen en cuenta el lugar ocupado por el interlocutor en la escala social; se podría considerar que en toda interacción verbal, incluso en los ámbitos amistoso, familiar, o los de mayor confianza, está presente un matiz de jerarquía. 
Península ibérica (Metrópoli)

En el siglo Xvi las relaciones de jerarquía se planteaban marcadamente a partir de los atributos de edad, sexo y posición social. Se obligaba a una observancia perfecta de este código, de modo que no utilizar el trato adecuado en ocasiones podía desembocar en problemas administrativos, o incluso "en episodios sangrientos, de los cuales tenemos testimonio en la literatura de la época" (Medina, 2006).

A partir del siglo xvi hay una progresiva evolución hacia usos asimétricos debido probablemente al surgimiento de una posición social media y, de manera paralela, de un mundo marginal. Dichos usos se explican fundamentalmente por la actitud de los sectores medios, muy preocupados por mantener las diferencias así como por la actitud de la baja nobleza, para la cual la pérdida de muchos de los valores tradicionales heredados conllevaba un ajuste en los tratamientos que no se permitía aceptar, por lo cual extremaba sus exigencias en el trato. De acuerdo con Medina Morales (2006), lo anterior trae como resultado la presencia en la interacción lingüística de un importante conjunto de tratamientos honoríficos graduales. ${ }^{7}$

...también se ha señalado como una de las causas importantes que motivaron el complicado sistema de tratamientos áureo, la presencia de los indianos o españoles americanizados que, por el poder econó-

\footnotetext{
${ }^{7}$ En general, las estructuras sociales de relevancia crean necesidades denotativas para la lengua correspondiente. De esta forma, si una sociedad está estructurada por un marcado sistema jerárquico, esto se reflejará en la formación de un sistema de (pro)nombres de cortesía.
} 
mico que ostentaron al volver a su lugar de origen, ejercieron presión en el habla y exigieron un trato que rivalizaba con el de los menos afortunados "hijos de algo" o baja nobleza que nunca salieron de la Península.

En los ejemplos planteados en este artículo veremos el caso de los conquistadores (soldados y misioneros) que permanecieron por décadas en la Nueva España y cuyos textos son parte de la literatura mexicana. En ellos se percibe un uso distinto de las formas de tratamiento del que les daban los habitantes de la península en la misma época.

los hechos más salientes que resultarían de un análisis lingüístico y sobre todo etnolingüística de la Información son el choque de dos culturas y el cambio cultural: aun empleando el lenguaje tradicional, los españoles hablan y escriben de manera distinta de las cosas nuevas en el Nuevo Mundo, en un mundo que no deja de cambiar (Lüdtke, 1994: 83).

En cuanto al extremo cuidado que cierto estrato de la sociedad peninsular tenía con los tratamientos hacia la segunda persona, es necesario resaltar el hecho de que Felipe II, rey de España, Sicilia y las Indias (de 1556 a 1598), mostró una constante preocupación por todos los asuntos de su reino, y enmendaba con meticulosidad todo documento que pasaba por sus manos. Este mismo cuidado lo extrapoló a los tratamientos. De acuerdo con Ebersole en su artículo "Interesante Pragmática de Felipe II (1586)": 
...tenemos la oportunidad de ver la meticulosidad con que intentaba definir la manera en que se tenía que empezar y terminar toda correspondencia de cualquiera de sus súbditos, desde la familia real hasta "el vasallo escriuiendo al señor" y "el criado a su amo" (1964: 803).

Pero, más allá de las formalidades en la correspondencia, Felipe II también se preocupaba por los tratamientos en el discurso, como se puede apreciar en el título del documento mencionado:

PRAGMATICA,/ En que se da la orden y forma que se ha de / tener y guardar, en los tratamientos y cortesías / de palabra y por escrito; y en traer coroneles, / y ponellos en cualesquier partes / y lugares // EN MADRID, / por Pedro Madrigal, Año de 1586. // Esta tassada a cinco marauedies el pliego. // Vendeseen casa de Blas de Robles, librero del Rey nuestro Señor. //

\section{Nueva España ${ }^{8}$}

La precisión cronológica que históricamente considera la época colonial a partir de la caída de México-Tenochtitlan, en 1521, es aplicable a la existencia formal de la Nueva España como entidad política y no lo es a otros aspectos. En lo social o cultural, por ejemplo, no se puede hablar de un período que empiece en 1521 y termine en 1821.

La conquista da inicio con la llegada de los españoles y su primera penetración en Mesoamérica. Entendida así, cu-

\footnotetext{
${ }^{8}$ Véase Nueva historia mínima de México ilustrada, 2008.
} 
brió un poco más de cuarenta años (repartidos en una fase inicial y otra de consolidación). Después de este primer período, habrían de pasar cincuenta años más para que Nueva España entrara en una etapa de madurez.

El deseo de los reyes de Castilla y León era reproducir, en la medida de lo posible, el entorno cultural y social de Castilla. El resultado del sometimiento de los naturales fue el establecimiento de una relación de dominio entre los españoles y cada uno de los señoríos. Hubo actividad política, negociaciones y ajustes violentos. Se instauró un gobierno representante de la corona española y el deseo de los monarcas se fue cumpliendo conforme los conquistadores consolidaban sus logros en nombre del rey. A partir de 1523 o 1524, numerosos españoles llegaron a la Nueva España, a ellos se les llamó "pobladores" para diferenciarlos de los conquistadores. También, ocurrió el arribo de los frailes de las órdenes mendicantes (franciscanos, dominicos y agustinos), y con ellos el establecimiento de las bases de evangelización y administración escolástica.

Uno de los aspectos de la consolidación de la conquista se hizo patente en el desplazamiento de los conquistadores de las posiciones formales del poder y su reemplazo por funcionarios con más preparación y comportamiento más civilizado. Esto ocurrió en el año de 1535.

En Nueva España también había una estricta observancia para el empleo del discurso asimétrico. Así se deja ver en los códices e historias que de la Nueva España elaboraron los misioneros. En la Historia general de las cosas de Nueva España, libro VI, Fray Bernardino de Sahagún da cuenta del cuidado que tenían los naturales para el empleo del discurso 
dirigido a sus dioses y su señor: del Capítulo I al Capítulo IX, describe el "lenguaje y afectos" que usaban para dirigirse a sus dioses (Sahagún, 2012: 326-353); en el Capítulo X están el "lenguaje y afectos" que se usaban para "hablar y avisar” al señor recién electo (Sahagún, 2012: 357). En los Capítulos XIII y XVI, respectivamente, los siguientes párrafos dan cuenta de este cuidado al hablar:

Capítulo XIII. De los afectos y lenguaje que usa el que responde por el señor a los oradores cuando el señor no se halla para responder. Es oración de algún principal o amigo o pariente del señor, bien hablado y bien entendido. Usa en ella de muchos colores retóricos (Sahagún, 2012: 368).

Capítulo XVI. De la respuesta que hacía un viejo principal y sabio en el arte de bien hablar, respondiendo de parte del pueblo, agradeciendo la doctrina y razonamiento del señor, y protestando la guarda de todo lo que se les havía dicho (Sahagún, 2012: 383).

Es en este contexto en el que se exploran y recopilan las formas de tratamiento para Nueva España.

\section{Formas coincidentes vs. diferencias en las regiones, y ocurrencias de relaciones sintagmáticas}

(SU), (TU), (VUESTRA) ALTEZA

Península ibérica (Metrópoli) - alteza

La forma alteza ocurre mayormente con cualquiera de los posesivos su y vuestra; además aparece en interacción con los clíticos, te, vos, os y le, en discurso que denota deferencia: 
Por tanto, téngale su alteza en prisión hasta tanto que te haga dar la isla [1516, Fernando Bernal, Floriseo. España, Javier Guijarro Ceballos, Centro de Estudios Cervantinos (Alcalá de Henares), 2003, CORDE]

Península ibérica (Metrópoli) - alteza - coincidencias y diferencias

Además del uso con los posesivos antepuestos su y vuestra, la forma alteza ocurre con $t u$, en interacción con los clíticos, te, vos, os y le, en discurso que denota deferencia. Puede suceder, en un mismo discurso, que al interlocutor se le llame tu alteza y su alteza. En el siguiente ejemplo vemos cómo su alteza es usado por un príncipe para referirse a su padre, y en el mismo párrafo emplea tu alteza, para hablar con su progenitor:

Muy contra razón habla su alteza, porque, veniendo yo preso, no nos veremos con el empacho que la diferencia de los estados suele causar, sino hablaremos con igual dolor, e como hombres igualmente apassionados buscaremos el remedio o el consuelo de nuestro mal. Y d'esta manera lo debemos tu alteza e yo buscar, porque yo, en la verdad, también estoy preso debaxo del poder del que a ti te traxo... [1516, Fernando Bernal, Floriseo. España, Javier Guijarro Ceballos, Centro de Estudios Cervantinos (Alcalá de Henares), 2003, CORDE]

En el párrafo siguiente se pone de manifiesto cómo un captor cuida sus modales con un prisionero de alto linaje, lo trata de $t u ́$, pero cuida en extremo las formas de tratamiento:

E como Pirineo oviesse sentido la gran ira e sobervia del soldán, porque no se dixesse que por modo de vengança él le hablava descortésmente, hablole con mucho concierto e más buena criança en esta manera: Di- 
zes, señor, que estaré muy alegre con la prisión de tu alteza, e más por averla hecho mi hijo, e otras cosas a que te responderé, si te pluguiere oírme. E a lo primero, en verdad, señor, que de la prisión de tu alteza me pesa mucho, porque por ser tú preso fue mi prisión más cierta e mi pena doblada... [1516, Fernando Bernal, Floriseo. España, Javier Guijarro Ceballos, Centro de Estudios Cervantinos (Alcalá de Henares), 2003, CORDE].

\section{Nueva España - alteza}

En una búsqueda simple en el CORDE, aparecen seis casos en cuatro documentos; una sola ocurrencia como tratamiento y los demás de uso referencial: se encuentra su alteza, en su mayoría, como referente para tercera persona; tu alteza, como característica inherente a una posición, no como tratamiento; y vuestra alteza, sí ocurre como forma de tratamiento en discurso respetuoso:

Guárdate, señor, de menoscabar y amenguar y amanzillar tu dignidad y valor, y la dignidad y valor de tu alteza y excelencia... [1576-1577, Fray Bernardino de Sahagún, Historia general de las cosas de Nueva España. México, Juan Carlos Temprano, Historia 16 (Madrid), 1990, CORDE]

Abuelas nuestras, dezidme, ¿es verdad que todavía tenéis desseo del deleite carnal? ¿Aún no estáis hartas, siendo tan viejas como soys? ¿Qué sentíades cuando érades moças? Dezídmelo, pues que estáis en mi presencia por este caso. Ellas respondieron: "Señor nuestro y rey, oya vuestra alteza, vosotros los hombres cessáis de viejos de querer la delectación carnal por haver frecuentádola en la juventud... [1576-1577, Fray Bernardino de Sahagún, Historia general de las cosas de Nueva España. México, Juan Carlos Temprano, Historia 16 (Madrid), 1990, CORDE] 
Nueva España - alteza - coincidencias y diferencias

Se encontró solamente una ocurrencia como forma de tratamiento: vuestra alteza:

A continuación y a manera de resumen final, se presentan los esquemas correspondientes a cada región.

\title{
(Su), (tu, (vuestra) alteza
}

Resumen PENínsUla ibérica (Metrópoli)

$\begin{array}{cc}\mathrm{su}+ & {[\text { alteza] }} \\ \mathrm{tu} & {[\text { alteza] }} \\ \text { vuestra }+ & \text { [alteza] }\end{array} \quad+$ te, vos, os, le

Esquema 1

\section{SEÑOR/SEÑNA}

\author{
Resumen Nueva EsPaña \\ vuestra \\ $+\quad$ [alteza]
}

Esquema 2

Península ibérica (Metrópoli) - señor/señora

Se encuentra como nominal para segunda persona y en interacción con los posesivos mi y mío. Señor/señora es la forma más frecuente para dirigirse al interlocutor, aparece con flexión de género y, en este caso, se usa sola o con el clítico $t e$, en un discurso de tuteo respetuoso; con los posesivos mi antepuesto y mío pospuesto; en la mayoría de los casos, aunque se trata de un tuteo no parece haber confianza o igualdad; en otros una extrema "intimidad respetuosa" como en el siguiente párrafo de la Celestina: 
...cuerpo gentil, que la vieja Celestina fue la primera que te tómo en las manos. Más nalgadas te di, señor, en este mundo, y besos, ${ }^{\star}$ que años tengo a cuestas; no venía la luna por acullá, * ni la callentura, ni el mal de ojo, que luego no venía un paje a llamarme para que te viesse y te curase y te desaojasse, que cada día te aojavan, que siempre fuiste como hecho de oro, * que no parescía sino un ángel, y agora pareces un serafin con essa crespa de oro... [1534. Feliciano de Silva, Segunda Celestina. Relato extenso diálogo y miscelánea, España, Cátedra (Madrid), 1988, CORDE]

\section{Península ibérica (Metrópoli)}

- señor/señora - coincidencias y diferencias

Aparece en interacción con los clíticos vos, os y le; en combinación con otros nominales como parentescos (antepuesto y pospuesto) en forma de tratamiento y en uso referencial; se antepone también a nombres propios:

Mi señora, no vos desmayéis, e yo os acomiendo a Dios, que miedo he que ya nunca más me veréis... [1501. Anónimo. Tristán de Leonís. Relato extenso novela y otras formas similares. España, María Luzdivina Cuesta Torre, Centro de Estudios Cervantinos (Madrid), 1999, CORDE]

¡O gran fortuna mía, que la gran falta que he cometido me haze dudar de perder el amor que en ti, hermano y señor, tenía ganada! Por lo qual soy venido a la fin de mis postrimeros días si tu mucha virtud no me quiere perdonar. Por que, señor hermano, te demando en merced que el amor y hermandad que entre ti y mí está no cese... Después dixo el Rey: 
- Hermano señor, manda de mí e de mis gentes lo que a ti paresciere que hazerse deve, que de todo lo que mandares serás obedecido por mí y por todos ellos... [1511, Anónimo, Traducción de Tirante el Blanco de Joanot Martorell, España, Martín de Riquer, Espasa-Calpe (Madrid), 1974, CORDE]

Lozana ¿Yo, señora? Pues más parezco a mi agüela que a mi señora

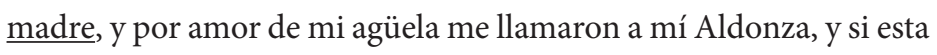
mi agüela vivía, sabía yo más que no sé, que ella me mostró guisar, [...] Mirá, señora tía, que su padre de mi padre decía: -¡Éstas son de mano de mi hija Aldonza! Pues ¿adobado no hacía?... [1528. Francisco Delicado, La Lozana Andaluza. Relato extenso diálogo y miscelánea. España, Claude Allaigre, Cátedra (Madrid), 1994, CORDE]

No te maravilles, señor Marcelo, deso, que puesto que algún tanto seamos parientes, y amigos que es más, no me hayas visto ni hablado hartos días... [1550. Pedro de Luján, Coloquios matrimoniales. Relato extenso diálogo y miscelánea. España, Asunción Rallo Gruss, Real Academia Española (Madrid), 1990, CORDE]

Como una forma de tratamiento para segunda persona, los títulos de nobleza empleados después de señor, aparecen para ambas flexiones de género, con interacción de los clíticos te, vos, os, le; se encuentran con mayor frecuencia después del masculino. Se hallaron pocos ejemplos en los que se antepone un superlativo al nominal masculino:

E porque esto no se escuse, ruego al señor duque te dé licencia para te combatir comigo... [1516. Fernando Bernal, Floriseo. Rela- 
to extenso novela y otras formas similares. España, Javier Guijarro Ceballos, Centro de Estudios Cervantinos (Alcalá de Henares), 2003, CORDE]

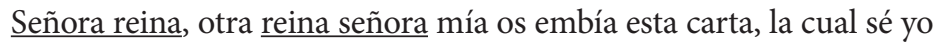
que os será mejor melezina que cuantas avéis tomado en ausencia de Floriseo... [1516. Fernando Bernal, Floriseo. Relato extenso novela y otras formas similares. España, Javier Guijarro Ceballos, Centro de Estudios Cervantinos (Alcalá de Henares), 2003, CORDE]

Potentíssimo señor, no te turbes, que nosotros ternemos manera cómo esta provincia venga a tu mano... [1503. Rodrigo Fernández de Santaella, Traducción del Libro de Marco Polo. Geografía. España, Juan Gil, Alianza Editorial (Madrid), 1987, CORDE]

\section{Nueva España - señor/señora}

Esta forma de tratamiento se encuentra en uso como nominal simple. Los ejemplos encontrados en los que señor y su flexión de femenino es forma de tratamiento para segunda persona en interacción con los clíticos propuestos, son siempre de discurso respetuoso y formal; se encuentran también con los posesivos, antepuestos y pospuestos para las dos flexiones de género:

Que no sé qué te quieren decir señor, ¿no sería bueno que fueses a casa a saber lo que quieren? [1541. Anónimo, Relación de las cerimonias y rictos y población y gobernación de los indios de la provincia de Mechu. Civilización, etnología, antropología. México, Leoncio Cabrero, Historia 16 (Madrid), 1989, CORDE] 
Hermosísisma pastora Santa Iglesia Mexicana con tal nueva, mi señora ocasión tendrás agora de estar contenta y ufana... [1574. Juan Pérez Ramírez, Desposorio espiritual entre el pastor Pedro y la Iglesia mexicana. Religioso. México, Anaya Book (Nueva York), 1972, CORDE]

\begin{abstract}
Nueva España - señor/señora - coincidencias y diferencias En los ejemplos también se muestran los títulos de parentesco únicamente pospuestos para masculino y femenino; antepuesto como forma de tratamiento solamente para el nominal señora; señor/señora, está también seguido de nombre propio; en cuanto al superlativo, en el caso de señor aparece antepuesto (simple y doble); y pospuesto; también con posesivo pospuesto de primera de singular más superlativo:
\end{abstract}

Y llegando a su casa, díjole: “¿Dónde están?” Y díjole su tía: “Señor, allí están, a las espaldas de casa. Allí les saqué de comer. ¿No sería bueno, señor, que te asentases y comerías un poco? ¿Cómo tendrás fuerza para respondellos?, que no sé lo que te quieren decir". Díjole Taríacuri: “Así es la verdad, señora tía”. Y hízole de comer unas poleadas, y trujóselo, y pusóselo delante, y tomó las poleadas y bibióselas de presto y comió. Entre tanto, su tía, cruzando las manos de miedo, decía entre sí: “Ay, ¿qué le diré?” [1541. Anónimo, Relación de las cerimonias y rictos y población y gobernación de los indios de la provincia de Mechu.... Civilización, etnología, antropología. México, Leoncio Cabrero, Historia 16 (Madrid), 1989, CORDE]

Doña Mariana de Morguiz a su hermano Diego Rodríguez, en Medina del Campo. Señor hermano: Yo acordé de escribir a v.m. por un mercader... [Enrique Otte, Cartas privadas de emigrantes a Indias 1540-1616. México, FCE, 1996, Carta núm. 6] 


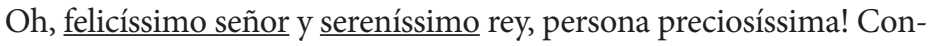
siderad que vais camino, y que hay lugares fragosos y peligrosos en el camino por donde vais, y que havéis de ir muy con tiento, porque las dignidades y señoríos tienen muchos barrancos y muchos resbaladeros y deslizaderos,... [1576-1577. Fray Bernardino de Sahagún, Historia general de las cosas de Nueva España. Historiografía. México, Juan Carlos Temprano, (Madrid), 1990, CORDE]

En el caso de Nueva España, el nominal de parentesco aparece antepuesto y pospuesto: en el masculino, de quince casos que arroja la búsqueda avanzada en el CORDE, para el siglo XVI, solamente tres concordancias corresponden a forma de tratamiento para segunda persona, el resto son referentes para tercera persona; el femenino tiene diez ejemplos de los cuales solamente uno es tratamiento para segunda persona.

A diferencia de las ocurrencias en península ibérica, el nominal de parentesco aparece solamente en un ejemplo antepuesto para la flexión de femenino y pospuesto, con mayor frecuencia, para ambos géneros, donde las ocurrencias predominan en el femenino. El uso de señor también ocurre para referirse al padre; no hay ocurrencias para referirse al hijo. En el caso de señora, ocurre también anteponiéndolo a nieta.

A la madre putativa, en este caso la partera, con conjunción copulativa de por medio, en una ocurrencia donde el lazo familiar-espiritual se refuerza con las formas de tratamiento:

Aquí responden la madre y parientas de la casada a la partera, y dizen: Muy amada señora y madre nuestra espiritual, hazed, señora, vuestro oficio. Responded a la señora y diosa nuestra que se llama 
Quilaztli y començad a bañar a esta muchacha. Metelda en el baño, que es la floresta de nuestro señor, que le llamamos temazcalli, a donde está y donde cura y ayuda la abuela, que es diosa del temazcalli, llamada Yoaltícitl. [1576-1577. Fray Bernardino de Sahagún, Historia general de las cosas de Nueva España. Historiografía. México, Juan Carlos Temprano, Historia 16 (Madrid), 1990, CORDE]

En los 179 casos en 22 documentos que arroja el cORDE en la búsqueda simple del nominal señora, el superlativo aparece en uso antepuesto al nominal femenino una sola vez:

Piadosíssima señora nuestra que os llamáis Chalchiuitlicue, Chalchiuitltlatónac, aquí ha venido a este mundo este vuestro siervo. [1576-1577. Fray Bernardino de Sahagún, Historia general de las cosas de Nueva España. Historiografía. México, Juan Carlos Temprano, Historia 16 (Madrid), 1990, CORDE]

Para el masculino, en la búsqueda simple en el CORDE (2,229 casos en 95 documentos) las ocurrencias de superlativo son más frecuentes, tanto antepuestas como pospuestas:

¡Oh, señor humaníssimo!, bien sabéis que la gente popular son como niños, que después de haver sido açotados y castigados lloran y solloçan y se arrepienten de lo que han hecho... [1576-1577. Fray Bernardino de Sahagún, Historia general de las cosas de Nueva España. Historiografía. México, Juan Carlos Temprano, Historia 16 (Madrid), 1990, CORDE]

Arroja, sin embargo un uso también frecuente de adjetivos, títulos de parentesco y posesivos, tanto antepuestos 
como pospuestos, en uso simple o en locuciones, para hablar, la mayoría de las veces, a la segunda persona femenina. En pocas coincidencias, aparece la forma señora, en interacción con te, vos, os; con le, solamente ocurre como referente para tercera persona:

Hija mía muy tierna, señora mía, havéis trabajado y vencido varonilmente, no sin gran trabajo...

Seáis bienaventurada y próspera, señora nuestra muy amada

De vos, señora, ha coxido una piedra preciosa; de vos ha tomado un plumaxe rico nuestro hijo Quetzalcóatl. Sea nuestro señor alabado porque con prosperidad apartó de vos...

[1576-1577. Fray Bernardino de Sahagún, Historia general de las cosas de Nueva España. Historiografía. México, Juan Carlos Temprano, Historia 16 (Madrid), 1990, CORDE]

A continuación y a manera de resumen final, se presentan los esquemas correspondientes a cada región.

\section{Señor/señora}

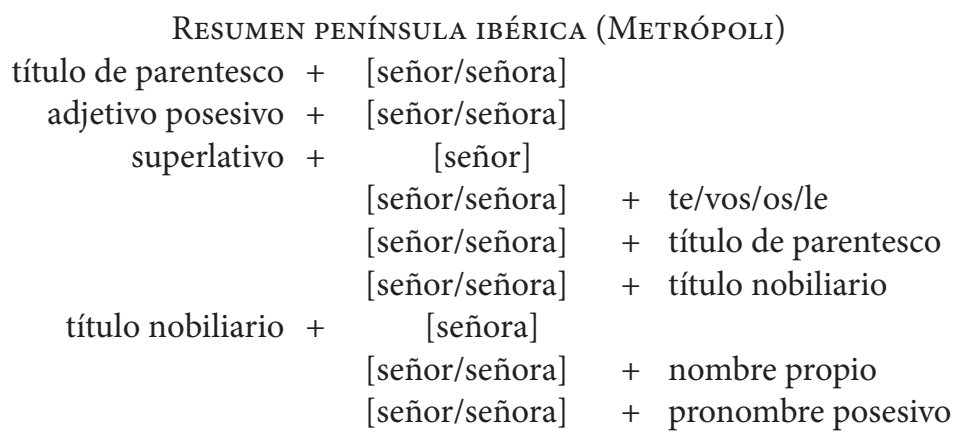

Esquema 3 


\begin{tabular}{|c|c|c|c|c|}
\hline \multicolumn{5}{|c|}{ Resumen Nueva España } \\
\hline título de parentesco & + & [señora] & & \\
\hline adjetivo posesivo & + & [señor/señora] & & \\
\hline superlativo & + & [señor/señora] & & \\
\hline superlativo doble & + & [señor] & & \\
\hline locución adverbial & + & [señora] & & \\
\hline adverbio & + & [señora] & & \\
\hline & & [señor/señora] & + & superlativo \\
\hline & & [señor] & + & te \\
\hline & & [señora] & + & te/vos/os \\
\hline & & [señor/señora] & + & título de parentesco \\
\hline & & [señor] & + & nombre propio \\
\hline & & [señor/señora] & + & pronombre \\
\hline & & & & osesivo \\
\hline & & [señor] & + & posesivo primera de \\
\hline & & [señora] & + & $\begin{array}{l}\text { plural + superlativo } \\
\text { posesivo primera de } \\
\text { plural }\end{array}$ \\
\hline
\end{tabular}

Esquema 4

Padre, madre, hijo, hija

Península ibérica (Metrópoli) - padre/madre/hijo/hija Las cuatro formas tienen un uso generalizado y cotidiano en la península ibérica. Por lo regular el discurso hacia los progenitores es asimétrico; en las expresiones comunes aparece con el posesivo pospuesto en tuteo; en interacción con vos y con os, siempre denotando deferencia; es mucho menor la cantidad de ocurrencias con el nominal madre.

Yo te confiesso, padre mío, que quando era niño tú me hazías enseñar a leer; pero no me negarás que, si hazía alguna travessura, que no me la consentías castigar; y de aquí nasció que, por dexarme tú hazer 
todo lo que yo quería siendo niño, te aya sido desobediente siendo ya grande... [1529-1531. Fray Antonio de Guevara, Reloj de príncipes. Relato extenso diálogo y miscelánea. España, Emilio Blanco, Turner (Madrid), 1994, CORDE]

En cuanto a hijo, el caso es similar al de padre: una gran cantidad de ejemplos en uso referencial de tercera persona y como nominal en discurso con segunda persona; es frecuente el uso simple o con el posesivo pospuesto; hija ocurre también en uso simple o con el posesivo pospuesto:

Pluguiere a Dios, hija mía, que pudiera yo pasar ese dolor por vos... [1574. Melchor de Santa Cruz de Dueñas, Floresta española. Relato breve tradicional. España, Maxime Chevalier, Crítica (Barcelona), 1997, CORDE]

El uso pragmático de los títulos de parentesco es asimétrico de hijos a padres; pueden usar el tuteo, el voseo, o el clítico le, para el trato de usted, incluso otras formas como alteza, ejemplificado en este apartado, pero siempre el trato es notablemente deferente. En los casos de padre y madre, se encontraron los posesivos antepuestos y pospuestos que otorgan un matiz de familiaridad del hijo al padre. No se encontraron locuciones de ningún tipo agregadas a los títulos padre o madre.

En el discurso de padres a hijos, se registra lo siguiente: hijo se halla solo, con posesivo pospuesto para acercarlo al interlocutor y con locuciones adverbiales que matizan cariñosamente el discurso, aunque sea una reconvención. Hija, además de las características anteriores, agrega adjetivos 
antepuestos, lo que imprime un rasgo de más intimidad y cariño en el discurso hacia las hijas. No se han encontrado, hasta el momento, matices de rudeza o desprecio en discurso entre primera y segunda persona padre/madre-hijo/ hija.

\section{Península ibérica (Metrópoli)}

- padre/madre/hijo/hija - coincidencias y diferencias

En una búsqueda simple para padre, el CORDE arroja 22,966 casos en 1,395 documentos; para madre 769 casos en 36 documentos, hijo nos da 1,214 casos en 39 documentos, hija 378 casos en 27 documentos. Viendo los números, "en bruto", sin distinción de uso referencial para tercera persona o forma de tratamiento para segunda, es claro que el discurso hacia los varones tenía una mayor incidencia y, por lo tanto, cabe la posibilidad de usos diversos.

En el siguiente ejemplo, el hablante llama padre mío a Dios, y a su progenitor se refiere como mi padre. El solo hecho de anteponer o posponer los posesivos le dan un matiz de mayor asimetría al primero.

Y más, padre mío, confieso yo, indina pecadora, aver pecado, que tomé del tesoro de mi padre sin su licencia y voluntad, para dar a Tirante, porque se mostrase entre los grandes señores del Imperio más rico y liberal. [1511, Anónimo, Traducción de Tirante el Blanco de Joanot Martorell, España, Martín de Riquer, Espasa-Calpe (Madrid), 1974, CORDE]

Con mucha menos frecuencia, aparece el posesivo antepuesto a padre, como forma tratamiento: 
Ruego a vos, mi padre — dixo Frisol—, que me digáys cómo fuestes desterrado o qué vos dixeron de mí. [1511. Anónimo, Palmerín de Olivia. Relato extenso novela y otras formas similares. España, Giuseppe di Stefano, Università di Pisa (Pisa), 1966, CORDE]

Hijo, ocurre con el nombre propio, y locuciones adverbiales pospuestas, para matizar con expresiones cariñosas una amonestación:

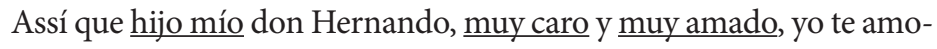
nesto y te conjuro, por el acatamiento que debes al desseo de la salud de tu padre y de tu madre [1535-622. Anónimo, El sumario de lo que contiene la historia de la comedia del duque don Alonsso y desta cassa, y el pr. Documentos notariales. España, Teresa Ferrer Valls, UNEDUniv. Valencia-Univ. Sevilla (Valencia), 1993, CORDE]

Hija, aparece, en ocasiones, con un adjetivo antepuesto y nombre propio pospuesto, para denotar amor filial, como en el caso del ejemplo:

Oye bien mis palabras, amada hija mía Politania, y en tu corazón las conserva. Dime: ¿quién piensas que es tu padre y madre? [1566. Juan de Timoneda, El Patrañuelo. Relato breve tradicional. España, Ma. Pilar Cuartero Sancho, Espasa-Calpe (Madrid), 1990, CORDE]

Nueva España - padre/madre/hijo/hija

Padre. Esta forma se ha encontrado como ocurrencia sola y únicamente un ejemplo con la forma en interacción con el posesivo pospuesto, pero como referencia. 
Madre. En una búsqueda simple, esta forma aparece 398 veces en 30 documentos en el CORDE. En uso se encuentra el nominal simple y usos referenciales para tercera persona.

Hijo. Tenemos 631 casos en 39 documentos en el CORDE. Aparece en uso solo, y con posesivo pospuesto. En vocativos ocurre con una mayor cantidad de elementos gramaticales.

Hija. Este término aparece solo, o con pronombre posesivo agregado al nominal:

Nota, hija mía, quiérote declarar lo que digo... [1576-1577. Fray Bernardino de Sahagún, Historia general de las cosas de Nueva España. Historiografía. México, Juan Carlos Temprano, Historia 16 (Madrid), 1990, CORDE]

En los códices y reseñas históricas, hay apartados específicos sobre la manera de tratar a las deidades, señores de México, Texcoco, Huejutla, auxiliares de los señores, había una "nómina de hombres malos" y "nómina de malas mujeres", y también apartados específicos para el trato a los integrantes de la familia por su posición jerárquica de parentesco. Podemos vislumbrar algo de esta organización en los ejemplos propuestos: padre se encontró como nominal, con los posesivos antepuesto y pospuesto, que permite acercar al hablante con su interlocutor; a madre, por el contrario, no se le agrega pieza léxica alguna. En ambos casos el discurso es muy respetuoso.

En el uso pragmático, hijo ocurre con adjetivo y pronombre posesivo, antepuesto y pospuesto, respectivamente. Hija, 
en este apartado, se encuentra únicamente con pronombre posesivo pospuesto. Los posesivos en cualquiera de las dos ubicaciones sintácticas, tiene un efecto de acercamiento.

\section{Nueva España - padre/madre/hijo/hija \\ - coincidencias y diferencias}

Estas cuatro formas de parentesco son notables para el caso de Nueva España debido a su austeridad en el uso. Si bien las cuatro son, aparentemente muy comunes, me ha parecido interesante mostrar algunas ocurrencias de su uso en textos de Nueva España que, si bien fueron escritos por los conquistadores y misioneros, pudieran tener una variante en sus reseñas debido al contacto con las lenguas indígenas. En la península, el uso de los cuatro nominales de parentesco, en lugar de tú, tiene un valor social de sumo respeto, incluso, cuando se habla de ellos con desprecio o con matices peyorativos, como veremos en los ejemplos. En los documentos abordados se observa que el uso se ciñe al trato consanguíneo con el rey-padre, padre, madre e hijo(a).

Padre. Se encuentra con nominal antepuesto:

No, señor, padre, ¿quién nos había de llevar? Todo está sosegado [1541. Anónimo. Relación de las cerimonias y rictos y población y gobernación de los indios de la provincia de Mechu. Civilización, etnología, antropología. México, Leoncio Cabrero, Historia 16 (Madrid), 1989, CORDE]

Por otra parte, un dato curioso es que, en una búsqueda simple, el CORDE, arroja 592 casos en 51 documentos para Nueva España; en el caso de la península ibérica, nos da 
22,966 ocurrencias en 1,395 documentos. De estos datos, habría que clasificar todavía los usos de parentesco.

El uso de esta forma es más "austera" en Nueva España que en la península ibérica; en los 592 casos, se encontraron usos referenciales para tercera persona, en su mayoría; no hubo formas acompañadas de superlativos ni de adjetivos $\mathrm{u}$ otros nominales

Hijo. Con posesivo antepuesto, no en función de adjetivo posesivo, sino como nominal:

PLACER. Madre, ¿no es mejor que dé con que curemos los dientes? CLEMENCIA. Vé, mi hijo y mi regalo. [1576. Fernán González de Eslava, Coloquio catorce de la pestilencia que dio sobre los naturales de México [Coloquios espirituales]. Drama religioso. México, José Rojas Garcidueñas, Porrúa (México), 1958, CORDE]

Hija. 237 casos en 24 documentos. Ocurre con varias locuciones pospuestas, para dar lo que pudieran interpretarse como matices de sentimientos y valores como amor, valor, pureza.

¡Oh, hija mía muyamada, mi palomita! [1576-1577. Fray Bernardino de Sahagún, Historia general de las cosas de Nueva España. Historiografía. México, Juan Carlos Temprano, Historia 16 (Madrid), 1990, CORDE]

Tú, hija mía, preciosa como cuenta de oro y como pluma rica salida de mis entrañas, a quien yo engendré, que eres mi sangre y mi imagen, que estás aquí presente [1576-1577. Fray Bernardino de Sahagún, Historia general de las cosas de Nueva España. Historiografía. México, Juan Carlos Temprano, Historia 16 (Madrid), 1990, CORDE] 
A continuación y a manera de resumen final, se presentan los esquemas correspondientes a cada región.

\section{Padre/madre/hijo/hija}

\begin{tabular}{|c|c|c|c|}
\hline \multicolumn{4}{|c|}{ Resumen PENíNSUla ibÉRICA (Metrópoli) } \\
\hline posesivo + & [padre] & + & posesivo \\
\hline & [padre] & + & te/vos/os \\
\hline \multirow[t]{3}{*}{ posesivo } & [madre] & + & posesivo \\
\hline & [hijo] & + & posesivo \\
\hline & [hijo] & + & locución adverbial \\
\hline \multirow[t]{3}{*}{ adjetivo } & [hija] & + & posesivo \\
\hline & [hija] & + & nombre propio \\
\hline & Esque & 5 & \\
\hline
\end{tabular}

\begin{tabular}{|c|c|c|c|}
\hline \multicolumn{4}{|c|}{ Resumen Nueva España } \\
\hline Nominal - & [padre] & + & posesivo \\
\hline \multirow{7}{*}{ Posesivo +} & [madre] & & \\
\hline & [hijo] & + & posesivo \\
\hline & [hija] & + & posesivo \\
\hline & [hija] & + & locución adverbial \\
\hline & [hija] & + & locución adjetiva \\
\hline & [hija] & + & metáfora \\
\hline & [hija] & + & diminutivo (simple o doble) \\
\hline
\end{tabular}




\section{Ocurrencias de relaciones sintagmáticas}

Las siguientes expresiones son formas de tratamiento hacia un interlocutor, se fueron extrayendo a lo largo de la investigación, y se asientan en este apartado debido a la particularidad que representan las estructuras sintácticas de cada uno de ellos, tanto en uso pragmático como referencial; todas representan un "patrón" sintáctico para forma de tratamiento en discurso asimétrico. En el caso de la península ibérica, el orden sintáctico [adverbio] + [adverbio] + [adjetivo], utilizado para realzar el título nobiliario, o en la contigüidad de los títulos príncipe, rey y señor, el hablante conjunta los elementos necesarios para distanciar a su interlocutor. Este "patrón" se ha hallado también en algunas epístolas escritas en la Nueva España.

\section{Península ibérica (METRóPoli)}

Lo cual se hizo. Y en la hora, despachó Mansirato un mensajero con una carta al soldán, su señor, que dezía ansí: Muy más poderoso príncipe del mundo: tu siervo e capitán Mansirato te hago saber cómo, teniendo yo esta Isla de las Perlas en mucho estrecho... [1516. Fernando Bernal, Floriseo. Relato extenso novela y otras formas similares. España, Javier Guijarro Ceballos, Centro de Estudios Cervantinos (Alcalá de Henares), 2003, CORDE]

Vista por el duque esta creencia, hizo aposentar al embajador según convenía e curar mucho dél. E como ovo estado allí un día, dio su embaxada al duque en esta manera: "Honrado duque, lo que el

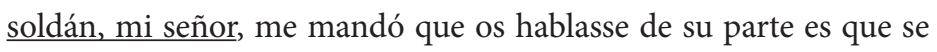


maravilla de vos, [...] Lo dicho es de mi señor el soldán. E lo de mi parte, señor, es que lo devéis hazer porque, allende que en esto ternéis vuestro estado seguro, estaréis más honrado que otro vassallo ninguno del soldán. E agora responded lo que mejor os pareciera." [...]Pues fue determinado entre ellos que el duque respondiesse al embajador por carta que embiasse al soldán, la cual dezía ansí: Muy poderoso señor, el duque de Atenas, vuestro vassallo... [1516. Fernando Bernal, Floriseo. Relato extenso novela y otras formas similares. España, Javier Guijarro Ceballos, Centro de Estudios Cervantinos (Alcalá de Henares), 2003, CORDE]

"Muy alto y muy poderoso príncipe rey y señor. Vuestra alteza sepa que ayer domingo a las dos horas de la noche falleció el señor rey, llamado por otro Rey que todos los reyes tenéis por mayor. Fágolo saber a vuestra real señoría, la cual me parece que luego sin ningún detenimiento, se debe partir para acá a más andar, porque así cumple al servicio vuestro; e por agora no es menester más. Nuestro Señor vuestra real persona guarde y muchos tiempos prospere y conserve. De Alcalá a 12 de deciembre del año de 1474." Y en el sobrescrito decía: "Al muy alto y poderoso príncipe rey y señor, mi señor el rey de Castilla, de León y de Sicilia, príncipe de Aragón."

[Carta de la reina de Castilla.] De allí a otros tres días llegó don Gaspar de Espés camarero del rey de Sicilia con carta de la reina, aunque en ella no se daba tanta prisa a la partida del rey como en la del arzobispo; $y$ sospechaban sus privados que se hacía... [1579. Jerónimo Zurita, Anales de la corona de Aragón. Segunda parte. Historiografía. España, Ángel Canellas López, CSIC (Zaragoza), 1977-1980, CORDE] 


\section{Nueva España \\ En Nueva España, a diferencia de la península ibérica, el or- den sintáctico pareciera mantenerse intacto, pero sigue un patrón de repetición:}

Oh, señora nieta e hija mía, paloma y doncella muy tierna y muy amada.Y luego el orador endereça su plática y oración a la señora rezién parida, y dize de esta manera: “¡Oh, señora nieta y hija mía, paloma y donzella muy tierna y muy amada! ¿Cómo estáis? ¿Qué sentís? Gran fatiga havéis padecido; gran trabajo havéis tenido; gran fatiga havéis pasado. Havéis ayudado, havéis os igualado, havéis imitado a vuestra madre la señora Cioacóatl Quilaztli... [1576-1577. Fray Bernardino de Sahagún, Historia general de las cosas de Nueva España. Historiografía. México, Juan Carlos Temprano, Historia 16 (Madrid), 1990, CORDE]

A la cesaría y católica magestad del emperador y rey de las Españas, nuestro señor. [Beatriz Arias Álvarez, El español de México en el siglo XVI. Documento C. México, Universidad Nacional Autónoma de México, 1997].

Después de esto el orador endereça su oración al padre del niño, diziendo de esta manera: "Señor nuestro y nieto mío, persona valerosa y preciosa. Por ventura os ofenderé, os daré molestia, y por ventura os seré embaraço para vuestras ocupaciones y exercicios, en unas pocas palabras con que os quiero saludar. [1576-1577. Fray Bernardino de Sahagún, Historia general de las cosas de Nueva España. Historiografía. México, Juan Carlos Temprano, Historia 16 (Madrid), 1990]

Nieta mía, muy amada y preciosa, como piedra preciosa, como chalchíuitl y zafiro, noble y generosa, ya es cierto agora que nuestro señor 
se ha [a]cordado de vos, el cual está en toda parte y haze mercedes a quien quiere. [1576-1577. Fray Bernardino de Sahagún, Historia general de las cosas de Nueva España. Historiografía. México, Juan Carlos Temprano, Historia 16 (Madrid), 1990, CORDE]

¡Oh, felicíssimo señor y sereníssimo rey, persona preciosíssima! Considerad que vais camino, y que hay lugares fragosos y peligrosos en el camino por donde vais, y que havéis de ir muy con tiento, porque las dignidades y señoríos tienen muchos barrancos y muchos resbaladeros y deslizaderos, donde los lazos están muy espesos y unos sobre otros, que no hay camino libre ni seguro entre los lazos y los pozos desimulados,... [1576-1577. Fray Bernardino de Sahagún, Historia general de las cosas de Nueva España. Historiografía. México, Juan Carlos Temprano, Historia 16 (Madrid), 1990]

Muy magnífico señor: Muy espantado me estoy por la poca cuenta que v.m. tiene en escribirnos, teniendo en México dos parientes tan parientes [Enrique Otte, Cartas privadas de emigrantes a Indias 15401616. México, FCE, 1996, Carta núm. 5]

Muy deseada mi señora madre: Por haber escrito largo en esta flota... [Enrique Otte, Cartas privadas de emigrantes a Indias 1540-1616. México, FCE, 1996, Carta núm. 68]

En los siguientes casos se presenta un tuteo irrespetuoso que aparece en los Coloquios espirituales, escritos por Fernán de Eslava.

JUAN. ¿Pues tú te tomas conmigo, tú, bellacazo, fullero?

LOPE. ¿Tú ganarme mi dinero? 
DOCTOR. Acabe, sea su amigo.

LOPE. Digo, señor, que no quiero.

DOCTOR. Por mi vida, caballeros: miren que están enojados.

LOPE. ¡Oh, pésete de mis pecados que me ganó mis dineros con los naipes floreados!

JUAN. ¿Entendiendo mis hazañas este conmigo se toma? ¡Oh, reniego de Mahoma! Sacaréle las entrañas y haré que se las coma [1583. Fernán González de Eslava, Coloquio sexto que se hizo para la fiesta del Santísimo Sacramento [Coloquios espirituales]. Drama religioso. México, José Rojas Garcidueñas, Porrúa (México), 1958, CORDE]

\section{Conclusiones}

Para llevar a cabo el distanciamiento del interlocutor, el hablante agrega en su forma o fórmula de tratamiento categorías gramaticales como posesivos de segunda de singular, y primera y segunda de plural, adjetivos en su forma simple o como superlativos o adverbios. Estas locuciones, por su uso continuo de acuerdo con los estándares sociales, se convierten en tratamientos y el patrón se fija en la lengua para formar el inventario de las formas y fórmulas de tratamiento en determinados períodos históricos de ambos lugares de estudio.

También es notable la diferencia en la cantidad de ocurrencias que nos brinda el CORDE en una búsqueda simple para los tratamientos comentados en este artículo. Si bien no todos los casos son formas y fórmulas de tratamiento, sí nos da una pauta sobre su frecuencia en el discurso cotidiano, 
tanto en la península ibérica como en la Nueva España. Por ejemplo, 47,945 ocurrencias para señor en la península ibérica vs. 2,229 de señor en la Nueva España.

Llama la atención el uso de los clíticos te, vos y os, y de los posesivos antepuestos $s u, t u, v u e s t r o(a)$ a, nuestro(a) para dirigirse a la segunda persona; en los ejemplos mostrados, el tuteo no parece mermar la distancia entre el hablante de menor rango o consanguineidad y su interlocutor.

Un indicativo de la posición de la mujer en la sociedad española y mexicana podría ser la menor cantidad de ocurrencias conteniendo el uso de nominales femeninos.

En la península ibérica, las disposiciones monárquicas relacionadas con la manera en que debía tratarse a los interlocutores de mayor jerarquía y la existencia de diversas clases sociales marca una distinción en el uso de los tratamientos, no obstante, en ocasiones estas diferencias no son absolutas, sobre todo pudieron haberse dado estratos o locaciones, donde se facilita la intercomunicación entre clases sociales y, por tanto, el ajuste de modelos; es notable la convergencia o acomodo del hablante al interlocutor. Lo anterior puede apreciarse en las ocurrencias y relaciones sintagmáticas planteadas para el tratamiento generalizado señor/ señora. Estos nominales interactúan con una gran cantidad de locuciones y piezas léxicas, en discurso deferente y respetuoso, pero mantienen el orden sintáctico establecido aun con la variedad de combinaciones.

Para Nueva España, tomando en cuenta los 90 años que ocuparon las fases inicial, de consolidación y madurez de la conquista, el siglo Xvi nos ofrece formas y variantes de contacto lingüístico y esto puede explicar el "juego" que los pro- 
pios peninsulares dan a la lengua y que los distancia ya de los que nunca salieron de la península ibérica. Este contacto se percibe en la manera en que fueron traducidos los usos de la lengua mexica y la manera como se asentaron en los códices Florentino y Matritense. Antes de ser la Nueva España, México sí tenía ciertos usos específicos de tratamiento para dirigirse a sus dioses y señores, así como a cada uno de los miembros de la familia; si bien no eran formas y fórmulas, sí podríamos hablar de "estructuras" específicas de la lengua que le daban los "colores retóricos" mencionados por Sahagún.

Como en la península ibérica, señor/señora tiene un uso común y cotidiano en México, de ahí la gran cantidad de combinaciones halladas en los casos propuestos. El caso llamativo en Nueva España es hija, pues se encuentra "aderezada" con piezas léxicas y locuciones únicamente pospuestas que conforman una forma de tratamiento "descriptiva": [posesivo], [locución adverbial], [locución adjetiva], [metáfora] y [diminutivo]; pueden encontrarse solas o en interacción, incluso repetición continuada de locuciones.

Lo expuesto permite confirmar la existencia de los cuatro ámbitos propuestos en esta investigación.

a) La monarquía, en España, donde el uso de títulos, incluso entre miembros del mismo grupo cuando no hay igualdad; no obstante, se pueden usar otras formas de tratamiento con afecto; en Nueva España, con nominales aderezados con una considerable cantidad de categorías gramaticales con sintaxis poco usual.

b) El espacio jurídico-administrativo, en España, pudiera ser la clase media, con tendencia a formas 
ceremoniosas (señor mío) que en este ámbito son corteses y normales; en Nueva España, los estratos después de los señores, gobernantes de los señoríos.

c) El ámbito amistoso-familiar, en España, donde se da la preferencia por formas poco ceremoniosas, $y$ que acortan las distancias, aun entre desconocidos, pero manteniendo el discurso asimétrico; en Nueva España, las categorías gramaticales que se agregan a los títulos de parentesco, matizan cariñosamente el discurso. Pese a todo, en el espacio familiar, la tendencia al discurso asimétrico se da de hijos a padres, de sobrinos a tías, etc., en ambos países.

d) El alto clero, donde también proliferan los títulos ceremoniosos, aunque no se comentan en este artículo.

A través de este breve recorrido por el uso de nueve formas y varios hallazgos, es notable que un estudio de las formas de tratamiento de cualquier época pasa por el análisis de las formas y fórmulas nominales y pronominales. "A diferencia de estas últimas, que constituyen un inventario cerrado y están muy estudiadas, las nominales representan un inventario mucho más amplio" (Medina, 2002). Como hemos visto, junto a las formas y fórmulas nominales y pronominales "clásicas", los hablantes pueden agregar una considerable cantidad de piezas léxicas, independientemente de cuál sea su categoría gramatical y de cuál debiera ser su sintaxis, todo con tal de alejar o acercar al hablante y denotar la deferencia necesaria.

Es preciso señalar también que en un estudio diacrónico, las obras literarias, el género epistolar y los corpora electró- 
nicos nos brindan una oportunidad invaluable de conjuntar un gran número de ejemplos para el análisis.

Así, es posible demostrar que cuando el hablante establece un discurso asimétrico emplea diversas piezas léxicas, tantas como necesite, para emitir una forma o fórmula de tratamiento que puede involucrar hasta cuatro o cinco categorías gramaticales, repetidas o diferentes.

\section{Bibliografía}

Arias Álvarez, Beatriz (1997), El español de México en el siglo XVI, México, Universidad Nacional Autónoma de México.

Brown R. y A. Gilman (1960), “The Pronouns of Power and Solidarity”, en T. Sebeok (ed.), Style in Language, Cambridge, MIT Press, pp. 253-276.

Brown, P. y S. C. Levinson (1978), "Universals in language usage: Politeness phenomena", en E. N. Goody (ed.), Questions and politeness: strategies in social interaction, Cambridge, Cambridge University Press, pp. 56-311.

- (1987), Some universals in language usage, Cambridge, Cambridge University Press (Studies in Interactional Socio-linguistics, 4).

Castro, Amanda (2001), Los pronombres de tratamiento en el español de Honduras, Lincom Europa.

Carricarburo, Norma (1997), Las formas de tratamiento en el español actual, Madrid, Arco Libros.

Ebersole, A. V. (1964), "Interesante pragmática de Felipe II (1586), Hispania, 47, 4, pp. 803-805 <http://cvc. 
cervantes.es/literatura/aiso/pdf/06/aiso_6_2_033. pdf $>$ [consultado en diciembre 2012].

Escalante Gonzalbo, Pablo et al. (2008), Nueva historia mínima de México ilustrada, México, Secretaría de Educación del Gobierno del Distrito Federal, El Colegio de México.

Fontanella de Weinberg, María Beatriz (1970), “La evolución de los pronombres de tratamiento en el español bonaerense", Thesaurus, XXV, 1. Centro Virtual Cervantes. <http://cvc.cervantes.es/lengua/thesaurus/pdf/25/ TH_25_001_012_0.pdf> [consultado en marzo 2014]. Fontanella de Weinberg, María Beatriz(1971), "Laconstitución del paradigma pronominal de voseo", Thesaurus, XXXII, 2. Centro Virtual Cervantes <http://cvc.cervantes.es/lengua/thesaurus/pdf/32/TH_32_002_015_0. pdf $>$ [consultado en febrero de 2014].

- (1999), "Sistemas pronominales de tratamiento usados en el mundo hispánico", en Gramática descriptiva de la lengua española, Madrid, Espasa.

García Moutón, Pilar (1999), “Tratamientos en las cartas de Indias", en Morales-Cardona (ed.), Estudios de lingüística hispánica: homenaje a María Vaquero, San Juan de Puerto Rico, Universidad de San Juan de Puerto Rico, pp. 236-276.

JoNGE, R. DE (2005), "El desarrollo de las variantes de vuestra merced a usted", en Estudios de lingüística del español (ELiEs). Actas del II Congreso de la Región Noroeste de Europa de la Asociación de Lingüística y Filología de América Latina (ALFAL). 22. <http://elies.rediris.es/ elies22/cap7.htm> [consultado en marzo 2014]. 
Lastra de Suárez, Yolanda (1972), "Los pronombres de tratamiento en la ciudad de México", Anuario de Letras, $\mathrm{X}<\mathrm{http}$ ://www.revistas.unam.mx/index.php/ral/issue/ view/3076> [consultado en enero de 2014].

Lorenzo Ramos, Antonio (1981), "Observaciones sobre el uso de los pronombres en el español de Canarias", $I$ Simposio Internacional de la Lengua Española.

LÜDTKE, JENs (1994), "Estudio lingüístico de la información de los Jerónimos (1517)”, en J. Lüdtke (comp.), El español de América en el siglo XVI, Madrid / Fráncfort am Main, Iberoamericana / Vervuert, pp. 73-86.

Medina López, Javier (1990), "Sobre los conceptos de poder y solidaridad en las formas de tratamiento", en Ma. Á. Álvarez Martínez (ed.), Actas del Congreso de la Sociedad Española de Lingüística. XX Aniversario. Madrid, Gredos, t. II, pp. 630-638.

Medina Morales, Francisca (2004), "Las formas nominales de tratamiento en el Siglo de Oro. Aproximación sociolingüística”, en Memoria de la palabra: Actas del VI Congreso de la Asociación Internacional Siglo de Oro, Burgos-La Rioja, F. Domínguez Matito y M. L. Lobato López (coords.), vol. 2, pp. 1329-1341.

- (2006), "Análisis comparativo de las formas simétricas de tratamiento de los siglos XVI y xvir y las actuales", en M. Casado Velarde, Ramón González Ruiz y María Victoria Romero Gualda (coords.), Análisis del discurso: lengua, cultura, valores: Actas del I Congreso Internacional, vol. $2<\mathrm{http} / / / c v c . c e r v a n t e s . e s / l e n g u a /$ coloquio_paris/ponencias/medina.htm $>$ [consultado en abril 2013]. 
Medina Morales, Francisca (2010), "La metodología en los estudios sobre formas y fórmulas de tratamiento en español", en M. Hummel, B. Kluge y M. E. Vázquez Laslop (eds.), Formas y fórmulas de tratamiento en el mundo hispánico. México, El Colegio de México.

Moreno, María Cristobalina (2010), "Identidad social a través del tratamiento a lo largo de la historia del español. Propuestas metodológicas", en M. Hummel, B. Kluge, M. E. Vázquez Laslop (eds.), Formas y fórmulas de tratamiento en el mundo hispánico. México, El Colegio de México.

Oliveira, Sandi Michele de (2010), "La integración de la teoría y la metodología como desencadenante de un nuevo modelo de formas y fórmulas de tratamiento", en M. Hummel, B. Kluge, M. E. Vázquez Laslop (eds.), Formas y fórmulas de tratamiento en el mundo hispánico, México, El Colegio de México.

Otte, Enrique (1996), Cartas privadas de emigrantes a Indias. 1540-1616, México, Fondo de Cultura Económica.

Rigatuso, Elizabeth Mercedes (1987), “Dinámica de los tratamientos en la interacción verbal: preparación y apertura conversacionales", Anuario de Lingüistica Hispánica, III, p. 161.

- (1992), Lengua, historia y sociedad. Evolución de las fórmulas de tratamiento en el español bonaerense (18301930), Bahía Blanca, Universidad Nacional del Sur.

— (1993), "Las fórmulas de tratamiento en la relación amorosa del español bonaerense: una visión diacrónica (18301930)", Anuario de Lingüística Hispánica, IX, p. 257. 
Sahagún, Bernardino de (2012), Historia general de las cosas de la Nueva España I. Red ediciones S.L. Memoria <www.linkgua.com> [consultado en mayo 2013]. 
